\title{
Therapeutic drug monitoring of new formulation Kaletra in pregnancy
}

V Jackson*1, LJ Else ${ }^{2}$, SH Khoo², SE Gibbons'2, M Brennan'1, EO Connor ${ }^{3}$, N Boyle ${ }^{4}$, C Fleming ${ }^{4}$, S Coulter-Smith ${ }^{1}$ and J Lambert ${ }^{5}$

Address: ${ }^{1}$ The Rotunda Hospital, Dublin, Ireland, ${ }^{2}$ Department of Pharmacology, University of Liverpool, Liverpool, UK, ${ }^{3}$ The Mater Misericordiae University Hospital, Dublin, Ireland, ${ }^{4}$ University College Hospital Galway, Galway, Ireland and ${ }^{5}$ The Rotunda Hospital, The Mater Misericordiae University Hospital and University College Dublin, Dublin, Ireland

* Corresponding author

from Ninth International Congress on Drug Therapy in HIV Infection

Glasgow, UK. 9-13 November 2008

Published: 10 November 2008

Journal of the International AIDS Society 2008, I I (SuppI I):PI99 doi:I0.II86/1758-2652-I I-SI-PI99

This abstract is available from: http://www.jiasociety.org/content/II/SI/PI99

(c) 2008 Jackson et al; licensee BioMed Central Ltd.

\section{Purpose of the study}

The new $\mathrm{LPV} / \mathrm{r}$ tablet formulation has significant patient benefits over the old LPV/r SGC, including a lack of food/ fluid restrictions, no need for refrigeration and a reduced daily pill count. However, like many antiretroviral drugs, the pharmacokinetics of the new LPV/r tablet during pregnancy is poorly understood. Here we report total and unbound LPV plasma concentrations during pregnancy and at post-partum.

\section{Methods}

In this prospective, open-labelled study, pregnant HIVpositive patients received the $\mathrm{LPV} / \mathrm{r}$ tablet formulation as part of their routine pre-natal care. Demographic and clinical data were collected and LPV plasma (total) and ultrafiltrate (unbound) concentrations were determined in the first (T1) and/or second (T2) and/or third (T3) trimester using HPLC-MS/MS. Post-partum (PP) sampling was performed where applicable. Ante-partum and post-partum PK parameters were compared using a one-way ANOVA (for independent data sets) and a paired t-test (for paired data).

\section{Summary of results}

From January 2007, 33 women were enrolled in the study; $31 / 33$ received $\mathrm{LPV} / \mathrm{r}$ tablet at the standard dose of $2 \mathrm{tab}-$ lets BID. The remaining two patients were prescribed 4 tablets OD and 3 tablets BID, respectively. 30/33 women initiated LPV/r treatment during pregnancy. Median gesta- tion at initiation was 25 weeks. $3 / 33$ women were receiving HAART prior to pregnancy. Median baseline CD4 count was 349 (14-836). Median baseline viral load was 9,100 copies/ml $(<50-267,408)$.

$\mathrm{LPV} / \mathrm{r}$ (total and unbound) concentrations were determined in $1 / 33$ (T1); $10 / 33$ (T2); 29/33 (T3) and $8 / 33$ (PP) ( $\leq 12$ weeks) patients. $2 / 10$ patients at T2 and 3/29 patients at T3 fell below the recommended LPV MEC $(<1000 \mathrm{ng} / \mathrm{ml})$, respectively. Median total LPV concentrations at T2 and T3 were $2770 \mathrm{ng} / \mathrm{ml}$ (1759-4202) and $3371 \mathrm{ng} / \mathrm{ml}$ (2331-4310), respectively; and were significantly lower relative to LPV concentrations observed at PP [5352 ng/ml (2667-7293)] ( $\mathrm{p}=0.042)$. Equally, in a paired analysis of eight patients (T3 vs. PP), total LPV concentrations were significantly reduced at T3 vs. PP ( $\mathrm{p}=$ $0.021)$. However, no significant difference was observed in the \% unbound LPV at T3 [0.93\% (0.71-1.10)] vs. PP [0.96\% (0.81-1.19)].

\section{Conclusion}

Standard dosage of LPV/r during pregnancy resulted in adequate therapeutic drug levels in the majority women examined. In addition, the similarities in the percentage of unbound LPV in the third trimester versus post-partum suggest that the standard dose of $\mathrm{LPV} / \mathrm{r}$ is appropriate during pregnancy. Further research into this is required. 